\title{
Strategy Behind the Business Success of Amazon: A Case Study
}

\author{
Chukwuka Sunday Ukeni \\ Department of Business Management, Texila American University, Guyana, Zambia
}

\begin{abstract}
The success of any business is dependent on the strategy/strategies that are deployed in the operation of such a business. Strategy is a critical determinant of business success. Amazon.com is one of the most successful brands in the world; the company has been in business for over two decades and has recorded an unprecedented business success in human history. In this research work, the key strategy behind the success of Amazon will be extensively investigated. Given the unusual success rate of this organization over the past two decades and their high prospect for greater success, it becomes imperative to investigate the strategy behind this tremendous business success in-order to unveil and/or re-emphasize an established business principle that may not be obvious to many businesses. The purpose of this research is mainly to identify these strategies and extend further emphasis on the viability of such business strategies in order to strengthen existing research on the subject matter. Using the waterfall methodology, the history of the company will be reviewed, the financial reports, company memos, press releases, etc., will be analysed. The evolvement of the business from its inception as an online book retailer to its diversification into numerous other lines of businesses will be reviewed and analysed.
\end{abstract}

Keywords: Amazon, Brand, Customer, Management, Strategy, Success.

\section{Introduction}

The purpose of this research is primarily to fulfill part of the requirements of my MBA program on Strategic Management/International Business with Texila American University.

When the success of Amazon is considered and discussed today, it will be difficult to believe that it all started at its founder's garage. Yet that's exactly where Jeff Bezos floated the online bookstore that has now culminated into a worldclass phenomenon.

At the preliminary stages of the company, Bezos and his then employees would gather books and convey them to the post office themselves, and even after the company began to build warehouses and acquire more assets, many investors still wrote off the venture as dead on arrival, especially because of the dominance of brands like Borders and Barnes \& Noble, so it was believed they would be wiped out by the existing popular brands.
Instead, major brands like Borders and Barnes $\&$ Noble later filed for bankruptcy protection in 2011 and are almost no longer in business. Meanwhile, Amazon has not only excelled in their first line of business but has widened their reach to cover almost every conceivable kind of product, media, and service. Some study shows that as of 2018, it accounted for nearly half of online retail. This information retrieved from eMarketer further revealed that in that period, Amazon was laying the groundwork for a physical retail business.

In their last 26 years of operation, Amazon's progression from bookseller to the world's leading eCommerce marketplace has been mindboggling, even though - according to the architect of its rise - building the "everything store" was all part of the plan from the beginning.

Considering the outstanding success of the company as briefly highlighted above, the strategy behind this compelling business success 
is one that should not only go unnoticed but also worth studying, especially for a student seeking any form of degree in the field relating to the subject of strategy, such as Strategic Management.

The research takes a look at the Amazon brand as a case study. It covers the operation and activities of Amazon.com from the inception of the company to date, with an aim to identify the major strategy(s) behind its outstanding success in business. In the course of the study, the annual financial statements of the company were analyzed, as well as the company's policies on customer relationship management, human resource management, etc. A critical area that was given attention is the area of product development and how it has contributed to meeting the company's vision and goals. The results of the company's performance in line with its strategy and policy implementation was analyzed and presented in the study. The company's expansion programs and procedures from America to different parts of the world was analyzed, and the results were presented. Another vital area that was covered is a study of the founder of the company and his ideologies and how it has contributed to the business success. The experience and leadership style of the company as well as the organizational culture, was analyzed to understand how it has contributed to the entire business success. The study was concluded by highlighting sufficiently the key strategy that is behind the business success of the company and how the same strategy can be adopted by other businesses around the world, to drive the realization of their vision and goals. It also attempted to show how Amazon has consistently followed this strategy in its business operations to date.

There are various existing researches on Amazon and its business success, many of which were consulted during the research. However, this is an addition to existing research as it focused mainly on the key strategy(s) behind the success of Amazon and how it can be replicated by other businesses around the world.

\section{Materials and Methods}

Many researches have been conducted on the success story of Amazon.com, a 26-year-old brand with an outstanding business performance that sets a standard for the global business space in general and the e-commerce industry in particular. The company is the largest ecommerce business in the world today, and the evolvement of the brand over the years to reach its present level of success has caught the interest of many researchers, as such, it has become a major subject of research globally.

According to existing research and available information, Amazon.com officially began operation on July 16, 1995, as an online bookseller. By August 31 of the same year, the company had shipped books to all the 50 states in America and to the other 45 countries in the world. By December 1996, the company had reached 180,000 customers after its full year in operation, and less than a year later, in October 1997, it had one million customer accounts. The number of customer accounts has grown to over 76 million as at October 2020.

Although existing research provides elaborate information about the business strategy of Amazon, the key strategy(s) that has been consistent from the inception of the company till date, which in my opinion is largely responsible for the long-term success of the business, still needs to be further investigated. Furthermore, the business ideologies of the founder that have remained consistent to date also have to be investigated, as the outcome of these investigations will serve as an additional and effective tool (working principle) in the arsenal of strategic business consultants, CEOs, and business managers. The study of strategic management will come to life when such practical business strategies are investigated to validate the principles already taught and practiced in the field. 


\section{The History of Amazon.com}

According to [1], Amazon officially began in July 1995 by Jeff Bezos, who did not know much about the internet at the time (even though he was a graduate of computer science), but came across a statistic that the internet was growing at $2300 \%$, and was convinced by this statistics to take advantage of the opportunity. However, [2] found that the Amazon brand was actually born on July 5, 1994, but officially commenced operation in 1995. The findings of [3], also agree with this. However, it further reveals that the name Amazon.com was officially registered on November 1, 1994 by Jeff Bezos and his wife, after considering and registering domain names like Awake.com, Browse.com, Bookmall.com, and Relentless.com in an attempt to choose the best name for the brand. He also found that the name Amazon.com (co-named after one of the largest rivers in the world) was chosen by the founder because it was fitting to his vision of building the largest online store in the world.

\section{The Early Breakthrough of Amazon.com}

According to [2] Amazon went public at $\$ 18$ per share, giving it a valuation of $\$ 300$ million. However, after adjusting for three subsequent stock splits, the closing stock price of Amazon on their first day of trading was $\$ 1.96$. The Podean Marketplace on its website (June 2020) validated the above fact but also emphasized that If one were to have invested $\$ 1,000$ into Amazon shares (IPO) in 1997, those shares would have grown in value to over $\$ 1,137,000$ by the end of 2019. This illustration was done to provide further insight into the level of breakthrough Amazon has achieved.

[3], in his paper, disclosed that by December of 1996, Amazon's customer base had grown to an impressive 180,000, and by October of the following year, this figure had leaped to around $1,000,000$ registered accounts. He also disclosed that Amazon's revenues had reached around \$148 million in 1997, a significant jump from around \$16 million in 1996. Prior to this time,
Amazon had remained a private company. But Bezos soon realized that to sustain the company's growth, and he would need more than just private investment. To this end, in 1997, Amazon.com went public and was able to raise a whopping \$54 million on the NASDAQ exchange. In addition to the cash, the company leveraged on its high-flying stock to fund its aggressive growth and acquisition strategy. By 1998, Amazon's revenues had reached a record $\$ 600$ million.

Amazon's outstanding rise within such a short period of time catapulted Bezos into prominence. He was also chosen to be Time magazine's 1999 Person of the Year.

According to [2], as the demand for their products and services increased, Amazon unveiled a second distribution center in November 1997 at New Castle, Delaware, in order to widen to market coverage. The business soon spread to China, Germany, UK, etc. to about 152 countries of the world.

[4] found that Amazon expanded rapidly in other areas as well. Its Associates program, which provides a platform for other Web sites to offer merchandise for sale, whereby Amazon.com would fill the order and pay a commission, grew from a mere site in 1996 to more than 350,000 by 1999. [5], further reveals that In 2000, the U.S. toy retailer Toys "R" Us signed a 10-year business agreement with Amazon, valued at $\$ 50$ million per year, under which Toys "R" Us would be the sole supplier of toys and baby products on the service, and the brand's website would redirect to Amazon's Toys \& Games category.

\section{Financial Records and Performance of Amazon.com}

[3] and other researchers agree that Amazon.com did not make a single profit until the last quarter of 2001, despite the huge success that characterized the business venture. [4] added that this situation appeared to justify the early criticism and scepticism that met with the 
business at the onset from financial journalists and analysts who even went to the extent of referring to the company as Amazon. Bomb; Many of them claimed Amazon.com ultimately would lose in the marketplace to established bookselling chains, such as Borders and Barnes \& Noble, once they launched competing ecommerce sites, and the lack of profits until 2001 looked like a confirmation to these predictions. Moreover, [6] confirmed that the company did make its first quarterly profit of $\$ 5.8$ million in the fourth quarter of 2001, but this was dwarfed by large cumulative losses. He further presented the historical income statements, historical balance sheets, and the historical cash flow statements of the company from $1997-2001$ as follows:

1. Sales grew from $\$ 147$ million in 1997 to about $\$ 3.1$ billion in 2001 .

2. The average growth rate during this period was $141 \%$.

3. The gross margin during this period had averaged $21.68 \%$.

4. The ratio of marketing expenses to sales revenue had decreased from $16.33 \%$ in 1997 to $4.43 \%$ in 2001 .

5. Interest expenses had risen from $\$ 326,000$ in 1997 to $\$ 139$ million in the year 2001 .

6. Loss from operations had increased from $\$ 32,595$ in 1997 to $\$ 412,257$ in the year 2001.

7. Sales from books, music, and video had levelled off. But this was a very profitable segment. On the other hand, the electronics, tools, and kitchen segment were growing rapidly- but were not very profitable.

According to the Amazon financial statements published by Macrotrends [7], Amazon has gone ahead to remain profitable from 2001 till date. A review of the financial statements of the company in the last six years shows that the company generated a net profit of $\$ 8.5$ billion in 2015 , which grew to $\$ 12.3$ billion in 2016 , and further grew to $\$ 15.5$ billion in 2017 , and then to $\$ 27.7$ billion in 2018 and further grew to $\$ 36.3$ billion in 2019 and finally grew to $\$ 48.1$ billion in 2020. Although the year 2020 came with a global lockdown that resulted in a global economic crisis which led to a massive collapse of businesses, job losses, and an increase in the cost of operation as a result of palliatives, rebates, and welfare of workers, Amazon.com remained significantly profitable.

The mere fact that the company survived for six whole years without making any profit from its inception attests to the financial competence of the Management and the formidability of the business model and strategies.

\section{Products \& Services of Amazon.com}

A study of the research work of [3] and others on the products and service line of Amazon revealed that at the onset of the company, Jeff Bezos (Founder) knew he wanted to build an online retail market, but he wasn't sure what exactly to sell on the platform, however, after some research and consultations, he settled for books because they were easier to source, package and distribute. But then, Amazon was not the first company to hit on this business strategy. Another company, Computer Literacy (a Silicon Valley bookstore), commenced sales of its own wares online as far back as 1991, but the difference with the business model and approach of Amazon.com was that it offered users greater convenience, as it was structured to deliver online orders directly to the customer's address anywhere in the world.

Moreover, [4], discovered that although Amazon.com famously started as a bookseller, Bezos maintained from its inception that the platform was not merely a retailer of consumer products. On several occasions, he was found saying that Amazon.com was a technology company whose business was simplifying online transactions for consumers. And as a result of this, the company will begin selling more than just books. The company commenced the sales of music and video in 1998. Within the same year (1998), it commenced its operations 
internationally with the acquisition of online booksellers in countries such as the United Kingdom and Germany. In the year 1999, the company had commenced the sales of consumer electronics, video games, and other related products. In the year 2002, the company introduced the sales of fashion-related products and further launched Amazon Web Services (AWS); a service that initially offered statistical data on Internet traffic patterns, most visited websites, and other relevant statistics for developers and marketers. In the year 2006, the company widened its AWS portfolio by integrating the Elastic Compute Cloud (EC2), a service that rents out computer processing power in small or large increments. That same year, the Simple Storage Service (S3); a service that rents data storage over the Internet, was included in their overall package. S3 and EC2 recorded immediate success and helped to propagate the idea that companies and individuals do not need to own computing resources; they can rent them as needed over the Internet, or "in the cloud." For example, in 2007, immediately after launch, the S3 service had over 10 billion objects or files; five years later, it held over 905 billion objects. Today, AWS is serving a few of Amazon's major rivals, such as the likes of Netflix, which makes use of both S3 and EC2 to compute its video streaming service.

[4], further revealed that when Bezos founded his company Amazon.com, the strategy was not to move inventory around. However, in order to establish a measure of control over deliveries, the company in 1997 started keeping inventory in its warehouses. In the year 2000, the company introduced a system that allows small companies and individuals to market and sell their products through the resources of Amazon.com. By the year 2006, it had commenced its FBA (Fulfilment by Amazon) service, a service that manages the inventory of businesses that market and sell their product through Amazon.com. The growth of its inventory-management business influenced its purchase of Kiva Systems (a robotics company whose devices automate inventory-fulfilment duties) at a whooping sum of \$775 million in 2012. In 2007 Amazon.com introduced the sales of its own Kindle e-readers, which helped energize the e-book market. In the year 2011, the company launched a related but affordable tablet computer: the Kindle Fire, and by 2012 , the Kindle Fire was estimated to have accounted for over 50 percent of the tablets sold with Google's Android mobile operating system.

After operating its first full year of selling books in 1996, publishing firms commended the new service as a leverage for them to clear their backlog of slow-selling books. In the year 2009, the first publishing line of the company, known as Amazon Encore was introduced, and it gave priority to popular self-published books as well as books that are out of print. It also afforded individuals the liberty to publish their own ebooks. In the year 2011, its e-book drive resulted to the emergence of Amazon Publishing, which was set up with the goal to develop and publish its own titles. That year, it was discovered that the e-books on Kindle were outselling the printed books. Although many book publishers has continued to enjoy revenue surge through sales at Amazon.com, the company is however seen as a major competitor in their industry.

In the year 2017, Amazon.com disclosed that it has reached an agreement to acquire the supermarket chain - Whole Foods Market, Inc., in a deal valued at over $\$ 13$ billion. Nonetheless, despite the fact that they have reached out well beyond online retailing, the larger chunk of the company's revenues are generated through the sales of products online (though its most profitable segment remains AWS), and that has been the target for most of its investment. Over the years, the company has either acquired or invested hugely in many online retailers, such as the renowned shoe seller Zappos, which was purchased for $\$ 847$ million in 2009.

Perhaps one of the most successful and profitable initiatives of Amazon, as seen in the research work of [2], is the \$79-a-year loyalty 
program that includes free two-day shipping on any order, announced by Jeff Bezos in 2005. Today, Amazon Prime has more than 100 million members worldwide, and it is considered as one of Amazon's most valuable assets. According to the Podean marketplace, Prime has proven to be a massive success: it now has more than 112 million members across the globe. The beginning of Amazon Prime resulted to the widespread of concept of customer appreciation and loyalty towards the company. The vision and goal of the company on customer obsession and ultimate customer satisfaction became a reality through the Prime project. To put it simply, the convenience and ease that Amazon Prime offers is the ultimate expression of Amazon's quest to deliver absolute satisfaction to its customers. In the year 2019, an average member of Amazon Prime in the U.S. spent about $\$ 1,400$ on Amazon.

[2] also has it that after being blamed for the decline of independent bookstores across the country, Amazon in 2015 opened its own physical retail location in Seattle. The store was opened as part of their strategy to market the company's growing list of electronic devices as well as to sell their books. Amazon currently owns and controls about fifteen major bookstores in the United States.

According to [5], In November 2020, the company started an online delivery service exclusively for prescribed drugs. The service provides discounts of up to $80 \%$ for generic drugs and up to $40 \%$ for branded drugs for active Prime users. The products are available for purchase on the company's website or at over 50,000 bricks-and-mortar pharmacies in the United States.

As at today, Amazon.com has successfully developed a number of products and services available, some of which include: AmazonFresh, Amazon Prime, Amazon Web Services, Alexa, Appstore, Amazon Drive, Echo, Kindle, Fire Tablets, Fire TV, Video, Kindle Store, Music, Music Unlimited, Amazon Digital Game Store, Amazon Studios and AmazonWireless.

\section{The Business Concept and Strategies of Amazon.com}

A review of the research work of [6] the reason behind the initial location of the company in Seattle, as revealed by the founder, was because of the availability of a large pool of technical talent and its closeness to one of the largest book wholesalers within the region at Roseburg Oregon. This actually confirms the fact that at the onset, he was thinking about the company as a bookseller. In addition to this, the sales tax laws for online retailers at the time was also a contributory factor in deciding the location of the company. As a result of this, cities like New York and California were ruled out of the options. This particular decision led to the quick growth of Amazon, because the possibility of stiff competition, which is a major growth threat, was eliminated from the onset.

[6], further disclosed that at the first attempt to name the company, the name Cadabra was chosen by Bezos. However, he would later discontinue with this choice when it was erroneously written as cadaver by a lawyer he engaged. He chose Amazon considering that it begins with the letter A, which is not only easy to apprehend and spell, but also signifies something big. According to the Podean Marketplace (2020), the decision to go with the name Amazon was later followed by Bezos because the name was taken from the largest river in the world (River Amazon in South America), which depicts his vision to build the largest bookstore in the world. The idea was crystallized while he was going through the dictionary, giving attention and priority to names that began with the letter " $A$ " because he believed this would be to the advantage of the company to be listed higher in alphabetized lists. This reflects the leadership quality of the founder of Amazon, which explains why Amazon has remained at the top since it got there.

Various researchers, including [4], reveal that although Amazon.com famously started as a bookseller, Bezos maintained from the start that 
the company was more than that. He always brought the wider perspective of what Amazon.com represents, which according to him was a tech company operating with the goal of offering simplicity and convenience to consumers in doing online transactions. Their inclusion of more and more products widened their reach to more and more customers. This also reflects the leadership quality of the founder and explains the reason why the company introduced many other products and services that eventually positioned the company to become profitable with a record of consistent and significant growth from 2001 till date.

[6], presented the two elements of Amazon's vision as follows:

1. To build the world's most customer-centric company.

2. To establish a place where customers could buy anything.

In the words of Bezos, the vision was presented thus- "Our goal is to be Earth's most customer-centric company. I will leave it to others to say if we've achieved that. But why? The answer is three things: The first is that customer-centric means figuring out what your customers want by asking them, then figuring out how to give it to them, and then giving it to them. That's the traditional meaning of customercentric, and we're focused on it. The second is innovating on behalf of customers, figuring out what they don't know they want and giving it to them. The third meaning, unique to the Internet, is the idea of personalization: Redecorating the store for each and every individual customer. If we have 10.7 million customers, as we did at the end of the last quarter, then we should have 10.7 million stores." Again, the leadership quality of the founder is seen here, and Amazon has been able to effectively achieve this vision with the Amazon Prime project. This is the key strategy behind the success of Amazon.

[3] reports that the main goal of Amazon at the onset was to simply to offer convenience. The ease of searching, selecting, purchasing, and taking delivery of products from the comfort of your home, was an amazing innovation at the time. Another selling point for Amazon at the time was its recommended product function. By marketing products with the purchase history of users, they were able to significantly grow their revenue. The inclusion of initiatives such as product reviews by existing users further helped to foster a kind of "customer community" that made the site, and its wares, more appealing to potential customers.

\section{Research Approach}

This primary objective of this research was to investigate the strategy(s) behind the business success of Amazon.com, the largest online retail store in the world. The research was a basic one, but not new because numerous pieces of academic and business research exists, regarding the remarkable success story of Amazon.com. As such, the proposed research took the form of a new research but on an existing research subject. In order to fulfill and satisfy the above objective, a combination of qualitative and quantitative research approaches was used. Although this research is more qualitative because of the exploratory nature of the objective, however, quantitative data was also used to support some of the facts, figures, and statistics, like the financial statements of the company for the past 20 years. The research was be developed completely with secondary data that are descriptive in nature since all of the data needed have already been provided by previous researchers and from other valid sources like the company's website and Wikipedia.com.

\section{Data Collection}

In order to extensively answer the research question, existing data (documents, records, publications, etc.) was relied upon, since there are numerous data that have been put together already about the company by other researchers, due to the attention attracted by the company as a result of its remarkable success in the business and economic space. Hence, all the other forms 
of data collection was unnecessary for this research work. Materials that covered areas such as the history of the company, the business strategies and policies of the company - fully capturing the vision and mission statement of the company, as well as the financial statements of the company and records of key interviews with the founder and CEO of the company, was analysed in the research. Many of the data used were produced and published directly by the company (like the financial statements), while others were developed and published by other researchers. The materials were gathered from valid and trusted sources such as the company's website, Wikipedia, and other business-related websites and research papers.

\section{Data Analysis}

The data collected was analyzed using the content and thematic data analysis method. The data was broken down into about five different themes, and each theme was developed according to the most consistent information from the data.

\section{Results}

The study so far has led us to the answer to the research question. The success of Amazon is hinged on three key strategies:

1. Customer Centricity

2. Technology Focused

3. Exceptional Management

Amazon is known today as the largest and most successful e-commerce retailer in the western world, and they achieved this by building the best customer experience. The motto and mantra of Amazon is customer happiness. The mission statement captures it thus: do whatever it takes to make the customer happy. Amazon has embraced and deployed the best technologies available in achieving its mission. Initiatives like Amazon Prime, Amazon Robotics, the Buy Box, and a whole lot of other initiatives that define the remarkable success of the company are technology-based. More so, the consistency of the owner and the team of
Management experts at Amazon in pursuing the above vision and mission statements to date reflects the impact of running a business with an exceptional team of Management, and how such strategy can contribute significantly to the success of the business.

\section{Discussion}

The above-identified success strategies will each be discussed and analysed in line with Amazon's operations and activities. However, the key strategy that has contributed to the success of this company is Customer Centricity, and the other strategies were only developed to ensure this strategy is not only realized but realized in an unprecedented manner. Today, the success of Amazon has drawn the attention of the business world to the importance of making customers a priority as a strategy of success, and this idea has since grown into a business principle that is widely accepted by all available business research.

\section{Customer Centricity}

Customer centricity is an organizational strategy, model, and mind-set that places customers, rather than product or sales, at the center of the business. When a business is operated with a customer-centric culture, it doesn't think of customer-centricity as something to achieve later, neither do they think of it as the outcome of good customer service delivery. They approach customer experience strategically and intentionally, such that the customer is enthroned from the start. An organization that is customer-centric operates in such a way that every person and process within the entire organization: whether or not they are customer-facing, are involved in planning and delivering the customer experience. In a customer-centric setting, every employee is trained to focus on the delivery of exceptional customer experience in order to build loyalty and encourage repeat business. Although people often think about customer experience solely within the context of customer service, sales, 
marketing etc., it goes beyond that. True customer-centricity is an organizational approach where the job of every employee (including those that do not interface with customers directly), is done in the best interest of the customer. In a customer-centric organization, the customer is the priority and the center, and every employee functions with this understanding and focus. This is vital in achieving business success in the long term. The focus in decision-making and policy direction always puts quality customer experience at the center. There is a close relationship between the customer service practices of a company and its profits; according to [8], customer-centric companies are $60 \%$ more profitable than their counterparts. Customer centricity can be well explained with the aid of the following diagrams that present an accurate picture of what the concept is all about:

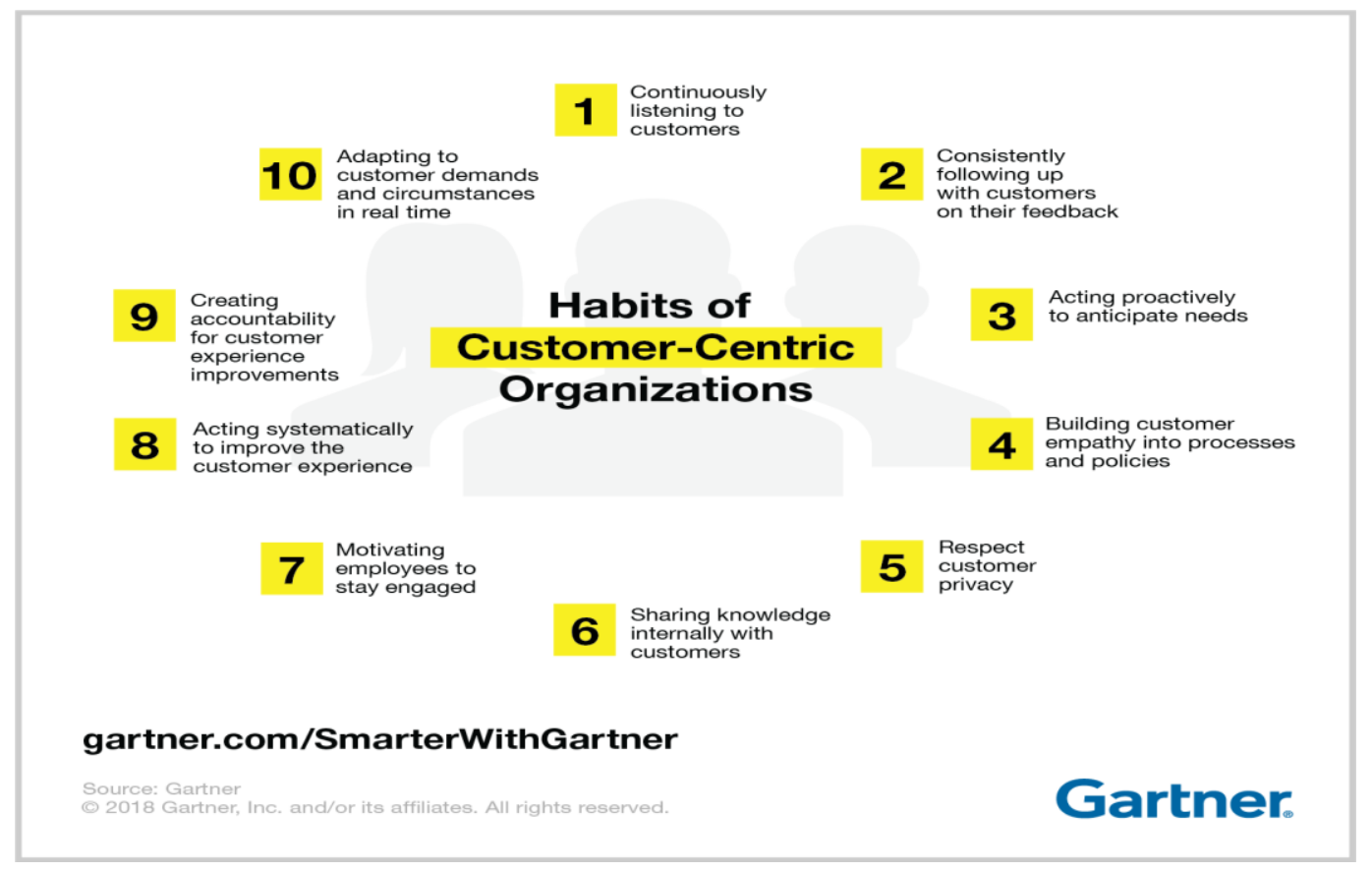

Figure 1. Habits of Customer-Centric Organizations

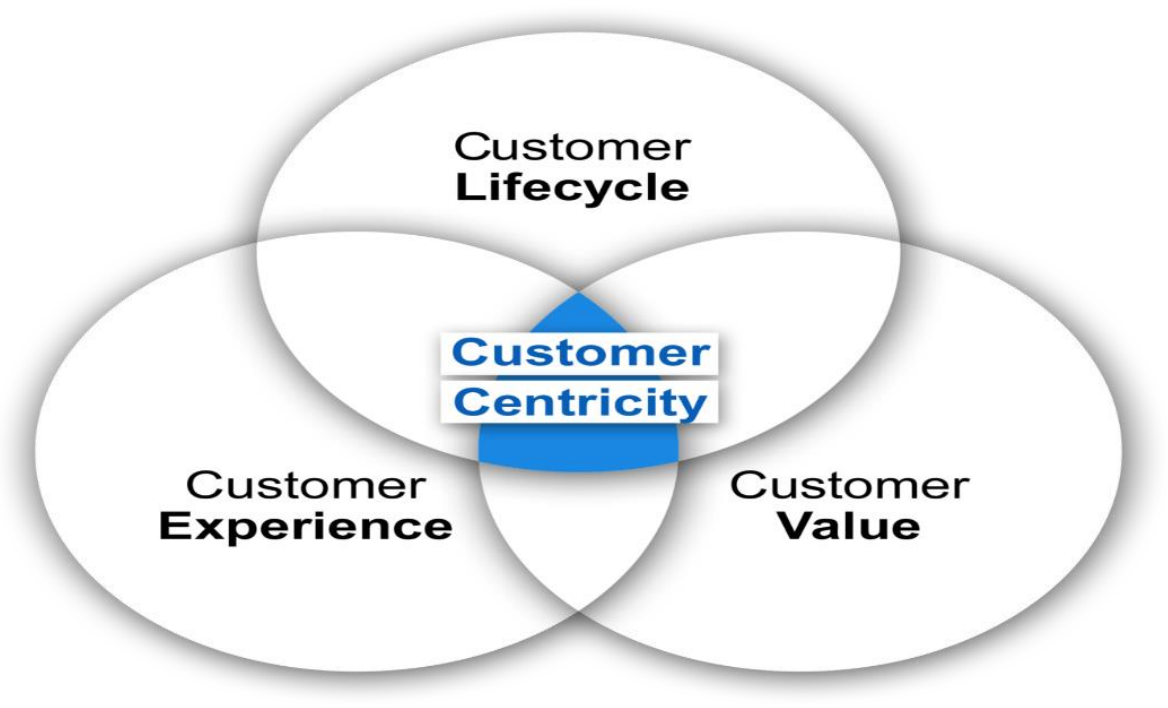

Figure 2. Customer Centricity 
Customer Centricity as described above involves putting the customer at the center of the vision statement of the company, as well as on the normal daily processes (such as the products/services offered, the mode of communication, the channels adopted, etc.) in order to strengthen the customer relationship.

There are three key elements that drive the concept of customer-centricity. The first element is customer experience. This is the sum of all experiences or interactions a customer has with a company, both online and offline. The second element is customer value, and this refers to the total value of a customer, both actual and potential value, both directly and indirectly (referral value like promoting a company, the influence on social media, etc.), and the third element is a customer life cycle, which refers to the evolution a customer goes through as defined by one or more aspects related to his or her needs (life stages, lifestyle, and relationship with company).

\section{The Culture of Customer Centricity in Amazon}

The description of the concept of customer centricity reflects the actual business practice of Amazon in its entirety. The business model and decision-making processes of Amazon are a practical definition of customer-centricity. For example, the key element of the vision of the organization is to build the world's most customer-centric company, and to a very large extent, this vision has been achieved today.

The approach to the successful implementation of this strategy is known as the Amazon Flywheel, and it is summarized below:

There are three major things customers consider when buying products online:

1. Large Selection: This ensures that consumers are able to find the products they are looking for.

2. Low Price: This ensures that the product is affordable to consumers.
3. Fast Delivery: This ensures that the consumers get their orders quickly.

If customers are given a quality (and consistent) shopping experience online, they will always return again and again and also refer their friends. This generates Traffic. Sellers will always flow with traffic, because they need to market their products to potential consumers. More sellers mean more product selection.

More product selection means a better Customer Experience (they have everything). With three of these elements in place, the growth of the platform is assured because of economies of scale, which implies lower cost structure, leading to lower prices, and the final outcome will be the ultimate growth cycle, achieved by offering the best Customer Experience to customers. Amazon's success was established on service to the customer and the customer alone.

\section{Product Selection}

Having the world's largest store entails having the world's best selection. But, this is easier said than done. The smaller number of products results in higher margins and higher returns while many others generate very little or none at all in most stores and product line. This is known as: the Fathead versus the Longtail problem. Limiting your product selection to those highdemand high ticket items as they generate the most profit might be tempting. The issue, however is that these high ticket items are not what consumers buy every day, and when they do, they always buy them from a retailer that is known and trusted. To build consumer's trust, you will have to offer a series of consistent and positive shopping experiences. Amazon seeks to earn consumer's loyalty so that they buy everything there. Amazon's success depends on the fact that it is two very different but seamlessly integrated shopping places at once: A store, like Walmart (with Vendors providing products to Amazon) and a marketplace, like eBay (with Sellers selling directly to consumers). 


\section{Price Factor}

Pricing is one of the most important factor that drives sales. As part of their commitment to provide a quality consumers' experience, they aim to offer the lowest price on the internet. They are succeeding with this. The Buy Box fosters competition within the platform to keep prices low. The Buy Box is a feature that has helped to keep the Amazon user interface tidy despite hosting a variety of sellers on the platform.

It works in such a way that each unique product has only one product page despite representing several listings. When the "buy" button is clicked by a user, the purchase is automatically directed to the seller who has won the Buy Box (red). The implication is that winning the Buy Box gives the seller a significant sales advantage, with the chances of winning about $85 \%$ of the sales for that particular item. The remaining sellers without the Buy Box will have to compete on the other $15 \%$ of the sales. Three key factors determine the winner of the Buy Box - price, rating, and delivery speed. To offer comparatively low pricing as a seller is one of the important determinants of winning the Buy Box. Uncompetitive pricing will significantly affect sales.

\section{Delivery Factor}

Asides from low pricing, the major delight of online consumers is quick delivery. Maintaining records of quick deliveries is instrumental in creating a consistent and reliable shopping experience. This is a challenge for many businesses.

There may be little (or no) infrastructure available in a business to achieve this, irrespective of the fact that they may be accustomed to selling only in bulk shipments or operating in a very small scale. These diverse circumstances notwithstanding, many users find it hard to distinguish between items "sold by Amazon" and "marketplace purchases". The implication is that for Amazon to get a consistent result, their shipping strategy will be adopted in selling other products.

The above arrangement is what is known as Fulfilment by Amazon (FBA). Controlling the process of storing, picking, packing and shipping enables Amazon to ensure that consumers get a quality delivery experience, and at the same time offering a solution to the sellers, who usually will struggle to deliver their goods going by the tough standards of Amazon.

This means that Amazon can always guarantee quick and accurate delivery as often as always. Any seller that opts in must ensure that their products are eligible for free shipping and Prime. Amazon Prime involves a subscription model that offers a 2-day free shipping on selected products. The service can currently be accessed in the United States, United Kingdom, Germany, Austria, India, Japan, Italy, Spain, and France. Amazon's idea is that the quicker the products arrive, the happier customers will be. This certainly seems to be true. Sellers often target to be listed on the Prime because it increases the likelihood of landing the Buy Box - and the lion's share of sales.

Amazon's brand is built on customer satisfaction. The goal is to earn the record of being the most customer-friendly company on the entire planet. The implication is that Amazon will be positioned as the company that offers the most convenience with the lowest prices and the best customer service out there.

\section{The Results of Customer Centricity at Amazon}

Amazon's strength is found in their relentless effort and commitment towards achieving a quality customer experience. Everything that Amazon does: every strategic move, every investment, is guided by its goal to be the most customer-centric company in the world. Every step, decision, and policy are geared towards benefiting and serving customers as best as possible. A lot of positive results have followed 
this initiative, some of which will be highlighted below:

\section{Data}

The sheer amount of data that Amazon has on consumers is mind-boggling. Beyond using the data to improve the efficiency of operations and improve the product offering, Amazon also sells the data for the purpose of publicity and advertisement through the Amazon DSP program.

\section{Prime Membership}

Consumers love Amazon, and there is high customer loyalty to the company, especially among the Prime members. Consumer Intelligence Research Partners (CIRP) discovered in their recent survey that over 100 million people resident in the United States have Amazon Prime accounts. I

The data also shows that approximately 58\% of Amazon Prime Members pay the full \$119 yearly fee, while $36 \%$ pay for the monthly fee, and the remaining $6 \%$ are on a free trial. Further data from CIRP has shown that Amazon Prime members spend double the amount spent by nonprime members do-averaging $\$ 1,400$ per annum.

\section{Worldwide Recognition}

Amazon wields enormous power in whatever new market it enters. Amazon's global brand recognition provides them with such leverage that it poses a danger to new markets. Amazon presently has a 31 percent market share in Germany. In the United Kingdom, the company has a 47 percent market share.

So far, Amazon has achieved and still achieving this goal, and this has resulted to a strong brand. In 2019, about 2,000 US shoppers were surveyed, and it was shown that about $89 \%$ of the customers prefer to buy their products from Amazon than from other e-commerce sites. The survey also discovered that Amazon was designed in such a way that it had become indispensable in the customer's journey, this is proven through their customer review system.

According to [9] : Two-thirds of respondents (66\%) often begin their search for new products on Amazon, whereas one-fifth (20\%) begin on a search engine such as Google. When shoppers are ready to buy a specific product, $74 \%$ go straight to Amazon.

\section{Customer Centricity and Corporate Social Responsibility (CSR)}

A comparison of the speech of Amazon's CEO in their annual report of 1997 after the company went public, and the speech of the CEO in their annual report of 2020 when the whole world experienced a deadly pandemic, reveals how consistent the company has been in achieving its vision of customer-centricity, and it also depicts the length they are willing to go to sustain this legacy. Amazon had clearly gone beyond creating the best experiences for their customers, to taking responsibility for their customers' welfare and survival when it mattered most through a measure of palliatives and CSR programs.

\section{Highlights of the CEO Speech in the 1997 Annual Report}

Amazon.com passed many milestones in 1997, and by the end of that year, more than 1.5 million customers had been served, yielding $838 \%$ revenue growth to $\$ 147.8$ million, and the market leadership was extended despite the aggressive competition.

The excerpts from Jeff Bezos speech in the 1997 annual report retrieved from [10] shed more light on the extent Amazon has gone (and is willing to go) in their customer-centric approach.

\section{Highlights of the CEO's regarding Amazon's response to the COVID-19 pandemic}

At the peak of the negative after-effects of COVID-19 in the year 2020, Jeff Bezos gave a rousing speech in this report to motivate, inform and forge a direction for staff, clients and 
shareholders. This further shows how far the company can go in maintaining their customercentricity approach. The excerpts from the speech can be found in [11].

\section{Technology}

In building a business that provides the best customer experience in the world, one strategy Amazon has embraced and deployed greatly to achieve this feat is focusing and leveraging on technology. The technology involves deploying scientific knowledge for practical purposes such as use in industry and other areas of life. In essence, anytime we use scientific knowledge to some productive end (to achieve a particular purpose), technology was in operation. Technology covers the actions taken to meet human needs, while science is concerned with the understanding of how the natural world works. It can also be seen as the collection of techniques, skills, methods, and processes which can be deployed towards the production of goods or services and also for the accomplishment of specific objectives. The knowledge of techniques, processes, and the like is one aspect, while the embedding of the processes and techniques towards the operation of machine or equipment without the knowledge of their workings is another aspect. The Internet is a very good example of technology because makes information available in real-time, which is accessible by anyone anywhere in the world in a matter of seconds.

\section{The Results of Technology Investment at Amazon}

One of the frequently asked questions about the operations of Amazon is how they manage to deliver so quickly, given the volume and the scope of their transactions. The answer to this question lies in their use of sophisticated technology. Amazon is currently controlling one of the major Fulfilment networks in the world, and this is as a result of the following:

1. Advanced Logistics.
2. Innovative technology, powered by Amazon Robotics.

3. 175 fulfilment centres worldwide operating 24 hours.

Logistics: The logistics system of Amazon is completely superior to any other logistics system available in the world, and this is one of the major factors that has enhanced their ability to achieve the goal of becoming the World's foremost customer-centric company. Amazon has invested heavily into logistical systems such as their various distribution centers near large cities in the world, advanced expert systems (robotics) for improved efficiency, etc.

Agility: Amazon has the capacity to make quick decisions, irrespective of its size. This enables them to always stay ahead of the game. This is achieved by a couple of built-in systems that ensure promptness and flexibility in their decision-making process. An example of such a system is the "two-pizza rule," which maintains problem-solving teams in a given number and encourages quick decision-making.

The reality is that the best in the world is not even second to Amazon. Currently, the company is making significant investments in new technologies, including Artificial Intelligence, to improve upon this already impressive system which surpasses that of long-standing logistics and shipping companies. This is one competitive edge that might be very hard to replicate.

In a press release dated March $4^{\text {th }}, 2020$, on the Amazon website, there was a detailed breakdown of the milestones they accomplished in their response to the outbreak of the COVID19 through the aid of technology.

Excerpts from this press release can be found in [12].

\section{Exceptional Management}

The CEO of Amazon - Jeff Bezos, is one of the best CEO's in the world today and has won the award for the best CEO in the world a number of times, especially during the early years of Amazon. His ideologies and consistency in 
pursuing the vision of the company are quite impressive. A review of his speech to the public for the past 23 years has remained progressive and consistent in achieving Amazon's vision. Bezos successfully built a Management team and inculcated in them the same enthusiasm and commitment towards achieving the Amazon vision, and he has successfully worked with them all these years to drive the company to its present level of success. This collaboration between a like-minded team of Management towards achieving the same goals and vision is one of the key strategies behind the huge success of the business.

Amazon has a policy of repeatedly testing ideas before streamlining their options to the most effective. The company is not afraid of failing when it comes to investing in the development of a product or service, even if there is a risk of failure surrounding that investment.

Below are some of the highlights of some of the comments of Jeff Bezos, which reflects a picture of the ideologies and commitment of the Management to the goal and vision and Amazon.

"The philosophy of Jeff Bezos is summarized in what he calls "Day 1" and "Day 2". This idea was conceived during the early days of the company. The building they occupied at the time was called "Day 1", and this name was given as a reminder that the company should always maintain "Day 1" mode in its functionality. The concept of "Day 2" is seen as a reversal of the "Day 1" concept, which is usually followed by irrelevance, as a result of a painful and excruciating process of decline and death."

"It remains Day 1." This statement was used to sign off the letter to the shareholders at Amazon by the Founder and CEO, Jeff Bezos. Bezos has promoted the "day 1" mantra for decades, and he says it as a reminder that the company should always operate like a start-up, even though the company has now grown in leaps and bounds.

Excerpts of the CEO COVID-19 speech in 2020 further reflected the strategic Management of the company by maintaining employee welfare and satisfaction; ensuring the safety of their employees. See [13] for further details.

\section{The Next Level in Delivering Customer Experience - Beyond Covid}

From the Jeff Bezos COVID speech in 2020, he further stated a variety of steps in achieving the vision and mission of Amazon. It was clearly presented to the public in the following headings:

1. Meet the Goals of the Paris Agreement on Climate Balance

2. Investment in Electric Vehicles to Achieve Climate Balance

3. Investment in Renewable Energy to Achieve Climate Balance

4. Investment in Packaging Waste Management \& Delivery Network to

Achieve Climate Balance

5. Investment in Efficient Data Centers to Achieve Climate Balance

For a full exposition on each of the steps, visit [14] for the foundational mission that powers this new pledge detailed in [15].

\section{Conclusion}

Amazon has become a household name in both books and music industries. It occupies a very high position of advantage amongst other smaller competitors. The company has achieved a remarkable feat in both books and the music market for life. It has expanded its operations as well as its profitability successfully by providing the best E-commerce ever, through proper knowledge of its customers, as well as the longevity of the relationships with its customers by providing a quality customer experience. These three aspects promise to keep Amazon conveniently afloat as well as to retain their dominant position in the industry, regardless of the competition they face.

It would be very tough and discouraging to keep up with Amazon, especially for smaller companies in the industry. They will have to restrategize by offering e-retail services that can compete with what is available in the market. 
This will be a pre-condition for their success in the industry. They will also need to find a way to ensure customer loyalty for the sake consistency.

Amazon has succeeded in building a perfect consumer system/platform. Their services offer much more than other platforms, while their charges are a lot more less than others (perhaps the lowest in the industry). They offer the best selection through the combination of a retailbased business and a marketplace kind of business; they offer the best price through the "buybox," initiative, and they ensure the quickest delivery through the FBA initiative offered to their sellers. They operate an effective business strategy known as "flywheel", which means that the more successful Amazon becomes, the more potential for they have to be successful.

The fact that Amazon currently controls about $50 \%$ of the market share in the United States alone and growing shows that their future in the industry is guaranteed. The implication of this is that as Amazon experiences further growth in the industry, this would lead to the growth of Amazon's sellers and vendors. Amazon's tendency to further evolve and grow is based on the fact that they are a platform, a seller and a brand all at once.

As it stands, the only way to effectively compete with Amazon will be to provide equal and better services and value in relation to their

\section{References}

[1]Zana Majed Sadq et al (2018), Analyzing the Amazon success strategies, (PDF) Analyzing the Amazon success strategies (researchgate.net), https://www.researchgate.net/publication/328689933 _Analyzing_the_Amazon_success_strategies.

[2] Lydia Depillis and Ivory Sherman (2018), CNN, Amazon's extraordinary evolution - CNN.com, https://edition.cnn.com/interactive/2018/10/business/ amazon-history-timeline/index.html.

[3] Christopher Mcfadden (2021), A Very Brief History of Amazon: The Everything Store, A Very Brief History of Amazon: The Everything Store | IE most important success metric: pleasing the customer, which currently seems impossible.

\section{Acknowledgment}

My acknowledgement goes to God Almighty for the opportunity to be alive to undertake a program.

I acknowledge Texila American University for providing the platform. My acknowledgement especially goes to the faculty and all my academic mentors for their assistance and help to complete this project.

I acknowledge my external guide, Dr. Anthony Orji, for making out time to assist in the completion and correctness of the project.

\section{Conflict of Interest}

The author certifies that there is NO affiliation with (or involvement in) any organization or entity that has any financial interest (such as honoria; educational grants; participation in speakers' bureaus; membership, employment, consultancies, stock ownership, or other equity interest; and expert testimony or patent-licensing arrangements), or non-financial interest (such as personal or professional relationships, affiliations, knowledge or beliefs) in the subject matter or the materials discussed in this manuscript.

(interestingengineering.com), https://interestingengineering.com/a-very-briefhistory-of-amazon-the-everything-store.

[4] Mark Hall (2021), Amazon.Com, Whole Foods Market | History \& Facts | Britannica

[5] Wikipedia (2021), Amazon (Company), Wikipedia the free Encyclopedia, https://en.wikipedia.org/wiki/Amazon_(company). [6] Sandeep Krishnamurthy (2002), Case \#1Amazon.Com- A Business History1 To Appear In"E-Commerce Management: Text And Cases," https://paginas.fe.up.pt/ipc/suporte/varios/amazon_fi nal.pdf. 
[7] Amazon Financial Statements 2005-2021, AMZN, MacroTrends,

https://www.macrotrends.net/stocks/charts/AMZN/a mazon/financial-statements.

[8] Cormac Hughes (2014), Deloitte, Customercentricity Embedding it into your organisation's DNA,

https://www2.deloitte.com/content/dam/Deloitte/ie/

Documents/Strategy/2014_customer_centricity_delo itte_ireland.pdf.

[9] Kiri Masters,(2019), Forbes, 89\% Of Consumers Are More Likely To Buy Products From Amazon Than Other E-Commerce Sites: Study, https://www.forbes.com/sites/kirimasters/2019/03/2 0/study-89-of-consumers-are-more-likely-to-buyproducts-from-amazon-than-other-e-commercesites/?sh=7c3074024af1.

[10] Jeff Bezos (1997), Amazon, Jeff Bezos’ 1997 Letter to Shareholders, https://s2.q4cdn.com/299287126/files/doc_financials /annual/Shareholderletter97.pdf.

[11] Jeff Bezos (2020) Jeff Bezos' 2020 Letter to Shareholders,

https://www.sec.gov/Archives/edgar/data/1018724/0 00119312520108427/d902615dex991.htm.

[12] Amazon (2020), Price gouging has no place in our store,

https://www.aboutamazon.com/news/companynews/price-gouging-has-no-place-in-our-stores.

[13] WashingtonAFP (2020), France24, Amazon moves to create lab for employee COVID-19 tests, https://www.france24.com/en/20200410-amazonmoves-to-create-own-lab-for-employee-covid-19tests.

[14] Amazon (2020), Jeff Bezos COVID-19 letter to shareholders, Beyond COVID, https://www.sec.gov/Archives/edgar/data/1018724/0 00119312520108427/d902615dex991.htm.
[15]Amazon (2019). Press release: Amazon Cofounds The Climate Pledge, Setting Goal to Meet the Paris Agreement 10 Years Early, https://press.aboutamazon.com/news-releases/newsrelease-details/amazon-co-founds-climate-pledgesetting-goal-meet-paris.

[16] Anke Moerdyck (2012), How customer centric is your organisation? InSites, https://insitesconsulting.com/blog/how-customer-centric-is-yourorganisation/.

[17] Andy Lane (2019), What is technology? OpenLearn - Open University, https://www.open.edu/openlearn/science-mathstechnology/engineering-andtechnology/technology/what-technology.

[18] Bahadir Kandemirli (2018), Amazon.com's Digital Strategies Amazon.Com Case Study, https://www.researchgate.net/publication/326132044 _amazoncom's_digital_strategies_amazoncom_case _study.

[19] Brian Roemmele (2017), Forbes, What Is Jeff Bezos's "Day 1" Philosophy? https://www.forbes.com/sites/quora/2017/04/21/wha t-is-jeff-bezos-day-1philosophy/?sh=ee51a8710523.

[20] Grace Baldwin (2020), Amazon, The Strategies Behind Amazon's Success, https://www.omniaretail.com/blog/the-strategiesbehind-amazonssuccess\#: :text=Amazon $\% 20$ sales $\% 20$ strategies, off er\%20a\%20consistently\%20great $\% 20$ experience.\&t ext=Much\%20like\%20Amazon\%20considers\%20cu stomer,so\%20to\%20do\%20its\%20Sellers. 